der Gegenwart. Entre 1990 y 2000 fue coeditora de la World New Music Magazine, anuario de la Sociedad Internacional de Música Contemporánea; y desde 2004 del sitio www.latinoamerica-musica.net, dedicado a la difusión de textos de y sobre música latinoamericana actual.

Es autora de los libros La obra sinfónica de Eduardo Fabini (1992) y Luis Campodónico, compositor (2000). Tradujo del alemán numerosos artículos y el libro Los signos de Schoenberg, de Jean-Jacques Dünki (Caracas: Monte Ávila 2005).

Las amistades no tienen que ver con pertenecer a una misma generación, lo que comprobé con mi maestro Cirilo Vila y con Graciela, con quien teníamos casi veinte años de diferencia. Lo mínimo que pude hacer por ella en mi rol de educador y director fue enseñar su música tanto en las aulas como dirigiendo sus obras de cámara en conciertos.

Sus composiciones se han interpretado en Alemania, Argentina, Bolivia, Brasil, Canadá, Chile, Colombia, Corea del Sur, Cuba, Escocia, España, Estados Unidos de Norteamérica, Francia, Gran Bretaña, Grecia, México, Rumania, Suecia, Suiza, Turquía, Uruguay y Venezuela. Parte de su producción fue incluida en fonogramas diversos editados en Alemania, Bolivia, Brasil y Uruguay. Tres de ellos son monográficos y aparecieron bajo el sello Tacuabé de Montevideo: Magma (1996), Libres en el sonido (2003) y Contra la olvidación (2012).

Desde su juventud Graciela Paraskevaídis tuvo grandes amistades en Chile. en las que se mezcló la política y la música. A su generación le tocó vivir episodios fuertes e impactantes de golpes militares que impusieron la brutalidad por las armas. Cada vez que venía a Chile su agenda estaba completa. Cultivó grandes amistades en la gran mayoría de los otros países de América Latina, en los que su figura creativa no era para nadie indiferente como tampoco lo fue su generosidad.

En el 2014 el sello Iberoamericana-Vervuert (Frankfurt-Madrid) publicó el libro Sonidos y hombres libres. Música nueva de América Latina en los siglos XX y XXI (En honor a Coriún Aharonián y Graciela Paraskevaídis) compilado por Hanns-Werner Heister y Ulrike Mühlschlegel. El mismo año 2014 la editorial Gourmet Musical (Buenos Aires) publicó Estudios sobre la obra musical de Graciela Paraskevaídis compilado por Omar Corrado. En 2015 el cineasta Ricardo Casas dio a conocer Libres en el sonido, un largometraje documental acerca de su vida y obra.

Si la libertad existe, independientemente de lo que cada uno piensa de ella, Graciela por cierto que sí la propiciaba. Si el cielo existe, estará habitado eternamente por esta inigualable mujer. Ella legó a todos quienes la conocimos la enseñanza de la fraternidad, y la creación a ultranza, junto con la intransigencia en practicar los principios de dignidad, ética y humanidad.

\author{
Eduardo Cáceres Romero \\ Facultad de Artes, Departamento de Música, \\ Universidad de Chile, Chile \\ kazeres@gmail.com
}

\title{
Lothar Siemens Hernández \\ (Las Palmas, Gran Canaria, España, 16 de agosto, 1941 - 28 de febrero, 2017)
}

La personalidad de Lothar Georg Siemens Hernández fue polifacética como la de un incontestable humanista de los tiempos modernos, intelectual de altos vuelos. A lo largo de su fecunda vida ejerció con extraordinario rigor actividades muy diversas: la de empresario, promotor cultural y, por encima de todo, la de musicólogo y compositor. En su propia familia encontró el caldo de cultivo de su dedicación vital: de su padre Lothar heredó el nervio empresarial; de sus antepasados Gregorio Millares Cordero y Agustín Millares Torres, el rigor intelectual y el amor a los libros y a las artes; y de su tía Lola de la Torre Champsaur, profesora suya en la adolescencia, la pasión por la música.

Desde muy joven pudo materializar de manera simultánea su dedicación a la música con su trabajo directivo en la empresa familiar "Siemens Maquinaria S. A.". Entre 1996-2004 fue presidente, en largos períodos, del Círculo de Empresarios de Gran Canaria. Y a partir de 2005 ha sido Presidente de Administración del Consejo Social de la Universidad de Las Palmas de Gran Canaria. 
Tras estudiar Filosofía y Letras se especializó en Musicología, Etnología y Prehistoria en la Universidad de Hamburgo, 1967, bajo la tutela del gran etnógrafo, egiptólogo y músico, discípulo de Kurt Sachs, Hans Hickmann. Por entonces fue comisionado por el propio Hickmann para preparar un programa de música española con vistas a ser editada fonográficamente dentro de la prestigiosa colección Archiv Produktion perteneciente al sello Deutsche Grammophon Gesellschaft. Con este propósito visitó ciertas instituciones y centros peninsulares donde de manera ininterrumpida se practicaba desde muy antiguo la música española, principalmente religiosa, del Medievo y del Renacimiento. Fue entonces cuando entabló relación fructífera con Santiago Macario Kastner, con Miguel Querol, con los padres Ireneu Segarra y Gregori Estrada, monjes de Montserrat y, muy particularmente, con Ismael Fernández de la Cuesta, recién nombrado Director del Coro de Monjes de Santo Domingo de Silos con quien, a lo largo de su vida, compartiría importantes proyectos musicológicos y mantendría una privilegiada relación de amistad. En el monasterio de Silos convenció a Fernández de la Cuesta para que realizara con su Coro de Monjes la grabación de cantos litúrgicos de tradición hispánica. Un disco LP llegó a editarse entonces en la colección Archiv con el título Gregorianischer Choral, el que alcanzó gran celebridad ya entonces, mucho antes de que esta y otras grabaciones de los monjes a cargo del mismo director se convirtieran, tras su digitalización y traslado al formato de CD, 1994, en un éxito mundial de ventas sin precedentes.

Lothar Siemens fue miembro muy activo del Grupo de Estudio Music Archaeology, creado a la sombra de su profesor de Hamburgo Hans Hickmann, cuya primera presidenta fue Ellen, la esposa de este, en el marco del ICTM (International Council for Traditional Music). En 2003 Siemens se doctoró en Historia del Arte - Musicología por la Universidad de La Laguna.

En las Islas Canarias ha ejercido una labor de liderazgo cultural incontestable. Fue director del Museo Canario desde 1972 hasta su jubilación. Dentro de él fundó el Departamento de Musicología al que dotó de un riquísimo fondo de partituras de autores canarios, así como de una fonoteca. Además, siguiendo el camino abierto por Lola de la Torre Champsaur ha realizado, junto con la musicóloga tinerfeña Rosario Álvarez Martínez, numerosos trabajos de investigación acerca de la música en Canarias, entre los que destaca el Proyecto RALS (Repertorio Audiovisual de Lectura y Sonido) que trata de recoger la historia de la creación musical del Archipiélago, y cuya parte fundamental la constituyen grabaciones digitalizadas de la música compuesta por personas nacidas en las islas Canarias o afincadas en ellas.

Lothar Siemens intervino muy decisivamente en la creación de la Sociedad Española de Musicología, junto con el padre Samuel Rubio, padre José López Calo y Pedro Calahorra, entre otros. La primera reunión promotora de dicha Sociedad tuvo lugar en Zaragoza en 1977. Desde entonces ha ocupado diversos cargos dentro de la Institución: Presidente de la misma (2007-2014), Director de la Revista de Musicología (1985-1992), vocal nato de la Junta de Gobierno (2014-), etcétera.

Es autor de unas 150 publicaciones entre libros, artículos y ediciones musicales. Estudioso del folklore canario, su gran interés por este tema se refleja en su tesis concerniente a las canciones de trabajo en Gran Canaria y en algunas compilaciones etnomusicológicas de campo, como son las transcripciones musicales de romances de las Islas Canarias, editadas por el profesor Maximiano Trapero.

Su febril actividad como empresario, gestor cultural y musicólogo investigador no le ha impedido ejercer una importante labor como compositor. Es de destacar su música vocal: canciones, obras corales y dos óperas, El encargo político y El moro de la patera. Entre las instrumentales es muy notable su Exhortación ante la muralla para tuba sola.

En 2005 donó su rico fondo bibliográfico y documental a la Biblioteca de la Universidad de Las Palmas de Gran Canaria. Su labor investigadora en el campo de la Musicología y Etnomusicología le hizo reunir una buena colección de documentos impresos y manuscritos, desde el siglo XVI al XXI. La catalogación del fondo se realizó entre fines de 2005 y mayo de 2008. En la colección se incluyen obras de gran valor, entre las que se destaca un incunable de 1494 y textos raros, únicos, del siglo XVI, impresos litúrgicos del siglo XVII y manuscritos, etc. Hasta poco antes de morir Lothar Siemens siguió donando documentos a la Biblioteca Universitaria. Entre publicaciones periódicas, monografías, música impresa, registros sonoros, videograbaciones, manuscritos, separatas, material gráfico y archivo informático se ha contabilizado 9314 volúmenes.

Lothar Siemens ha tenido numerosos reconocimientos públicos, señaladamente los siguientes: la Medalla de Oro del Gobierno de Canarias en el 2005; Can de Plata del Cabildo de Gran Canaria; Hijo Predilecto de la Ciudad de Las Palmas de Gran Canaria; Premio Canarias en 2014 y Medalla de la Universidad de Las Palmas de Gran Canaria (ULPGC) en 2016, un año después de dejar de ser 
Presidente de su Consejo Social; Socio de Honor de PROMUSCAN (Asociación de Compositores, Musicólogos, Intérpretes y Socios de Apoyo para la Promoción de la Música Culta de Canarias). Siemens también fue Académico Correspondiente de la Real Academia de la Historia (Madrid) por la ciudad de Hamburgo; Académico Correspondiente, asimismo, de la Real Academia de Bellas Artes Santa Isabel de Hungría de Sevilla y Académico de Número de la Real Academia Canaria de Bellas Artes de San Miguel Arcángel.

Ismael Fernández de la Cuesta Académico Numerario de la Real Academia de Bellas Artes San Fernando, Madrid, España chant@idecnet.com 